\title{
Corticosteroids in the treatment of acute exacerbations of chronic obstructive pulmonary disease
}

This article was published in the following Dove Press journal:

International Journal of COPD

3 May 2014

Number of times this article has been viewed

\author{
J Andrew Woods' \\ James SWheeler' \\ Christopher K Finch ${ }^{2}$ \\ Nathan A Pinner ${ }^{3}$ \\ 'School of Pharmacy, Wingate \\ University, Wingate, NC, USA; \\ ${ }^{2}$ Department of Pharmacy, Methodist \\ University Hospital, Memphis, TN, \\ USA; ${ }^{3}$ Harrison School of Pharmacy, \\ Auburn University, Auburn, AL, USA
}

Correspondence: J Andrew Woods

School of Pharmacy, Levine College

of Health Sciences, Wingate University,

5 I 5 North Main Street, Wingate,

NC 28I74, USA

Tel +I 7042338646

Fax + I 7042338332

Email a.woods@wingate.edu
Background: Chronic obstructive pulmonary disease (COPD) is a chronic and progressive disease that affects an estimated $10 \%$ of the world's population over the age of 40 years. Worldwide, COPD ranks in the top ten for causes of disability and death. Given the significant impact of this disease, it is important to note that acute exacerbations of COPD (AECOPD) are by far the most costly and devastating aspect of disease management. Systemic steroids have long been a standard for the treatment of AECOPD; however, the optimal strategy for dosing and administration of these medications continues to be debated.

Objective: To review the use of corticosteroids in the treatment of acute exacerbations of COPD.

Materials and methods: Literature was identified through PubMed Medline (1950-February 2014) and Embase (1950-February 2014) utilizing the search terms corticosteroids, COPD, chronic bronchitis, emphysema, and exacerbation. All reference citations from identified publications were reviewed for possible inclusion. All identified randomized, placebo-controlled trials, meta-analyses, and systematic reviews evaluating the efficacy of systemic corticosteroids in the treatment of AECOPD were reviewed and summarized.

Results: The administration of corticosteroids in the treatment of AECOPD was assessed. In comparison to placebo, systemic corticosteroids improve airflow, decrease the rate of treatment failure and risk of relapse, and may improve symptoms and decrease the length of hospital stay. Therefore, corticosteroids are recommended by all major guidelines in the treatment of AECOPD. Existing literature suggests that low-dose oral corticosteroids are as efficacious as high-dose, intravenous corticosteroid regimens, while minimizing adverse effects. Recent data suggest that shorter durations of corticosteroid therapy are as efficacious as the traditional treatment durations currently recommended by guidelines.

Conclusion: Systemic corticosteroids are efficacious in the treatment of AECOPD and considered a standard of care for patients experiencing an AECOPD. Therefore, systemic corticosteroids should be administered to all patients experiencing AECOPD severe enough to seek emergent medical care. The lowest effective dose and shortest duration of therapy should be considered.

Keywords: chronic obstructive pulmonary disease, exacerbation

\section{Introduction}

Chronic obstructive pulmonary disease (COPD) is a debilitating chronic condition of airflow limitation characterized by abnormal inflammation that is not fully reversible and is progressive in nature. The worldwide prevalence of COPD is estimated to be approximately $10 \%$ of individuals older than 40 years of age. ${ }^{1}$ In 2011 , there were an estimated 13 million adults in the US diagnosed with COPD. Alarmingly, there may 
be an equal number of Americans with the disease who have yet to be diagnosed. ${ }^{2}$ COPD is a leading cause of morbidity and mortality. The World Health Organization has identified COPD as the seventh-leading cause of disability and the fourth-leading cause of death internationally. ${ }^{3}$ In the US, COPD is now the third-leading cause of death, claiming approximately 138,000 lives annually. ${ }^{1,4}$

Given the prevalence and consequences of COPD, it is imperative to recognize its societal and economic impact. Continued tobacco use and dependence, along with an overall increase in life expectancy, allows the societal burden of COPD to continue to grow, with the most recent evidence estimating over 700,000 hospital discharges annually. ${ }^{5,6}$ In addition, the associated economic burden is vast. The most recent cost projections of COPD in the US alone were approximately $\$ 50$ billion, which included $\$ 20$ billion in indirect costs and $\$ 30$ billion in direct health care costs. ${ }^{5}$ A significant portion $(50 \%-70 \%)$ of the direct health care costs associated with COPD are attributed to exacerbations. ${ }^{7}$ In fact, it has been estimated that nearly three-quarters of COPD patients experience an exacerbation during a 1-year period, and that annual rates of exacerbations may be as high as 3.8 per person with COPD. ${ }^{8,9}$

While many acute exacerbations can be treated on an outpatient basis, some may require hospitalization. Lung function typically declines with each exacerbation, especially in patients requiring hospitalization. ${ }^{10}$ In accordance with a decline in lung function, the risk of hospital readmission or death significantly increases with each exacerbation. ${ }^{11}$ Effective strategies to reduce the incidence of COPD exacerbations and the duration of these exacerbations are essential.

The administration of corticosteroids has long been a mainstay of therapy for the treatment of an acute exacerbation of COPD (AECOPD). While the efficacy of corticosteroid administration in the treatment of AECOPD is established, the optimal dosing regimen (dose and schedule) is continuously debated. Given the incidence and burden of AECOPD and the contention regarding the optimal use of corticosteroids, the purpose of this review is to summarize published evidence regarding the efficacy, route of administration, and optimal duration of corticosteroid therapy in patients experiencing an AECOPD.

\section{Current guideline recommendations}

Although head-to-head comparison data are limited for evaluating corticosteroid selection and dose efficacy, all major guidelines recommend low-dose oral corticosteroids for exacerbations of COPD severe enough to warrant emergent treatment (Table 1). ${ }^{12}$ The GOLD (Global initiative for chronic Obstructive Lung Disease) international guideline recommends a dose of $30-40 \mathrm{mg}$ of prednisolone for 10-14 days during an AECOPD. ${ }^{5}$ This recommendation is mirrored in other national guidelines. For example, the UK National Institute for Health and Care Excellence 2010 COPD guidelines also recommends prednisolone $30 \mathrm{mg}$ daily for $7-14$ days. ${ }^{13}$ The Joint American Thoracic Society/European Respiratory Society guideline recommends 30-40 mg of prednisone for 10-14 days. ${ }^{7}$ Similarly, the Canadian Thoracic Society recommends 25-50 mg of prednisone, or an equivalent dose, for 10-14 days for patients with moderate-to-severe AECOPD. ${ }^{14}$ These recommendations are based on several small studies that validate the efficacy of low-dose corticosteroids in AECOPD,${ }^{13,15-17}$ as well as favorable pharmacokinetic parameters that give oral corticosteroids excellent bioavailability. ${ }^{18}$

\section{Materials and methods}

A search of PubMed Medline and Embase (1950-February 2014) was performed without limitations using the search terms corticosteroids, COPD, chronic bronchitis, emphysema, and exacerbation. Additional literature was identified through the review of references found in the primary literature search. Identified randomized, placebo-controlled trials, meta-analyses, and systematic reviews were reviewed for information regarding outcomes, duration, and route of administration of systemic corticosteroids in the treatment of COPD exacerbation.

\section{Efficacy of systemic corticosteroids}

Early clinical trials evaluating the efficacy of systemic corticosteroids in the treatment of COPD offered conflicting results. ${ }^{19-25}$ While some published reports documented efficacy in the administration of systemic corticosteroids to patients with COPD, ${ }^{20,21,25}$ others conveyed little if any benefit. ${ }^{19,22-24}$ However, the interpretation and applicability of early data are limited by a dearth of randomized, placebocontrolled, blinded studies, a lack of clearly defined end points, and assessment of efficacy in multiple COPD patient populations.

Because early clinical trials almost exclusively evaluated the effect of therapy with corticosteroids in patients with stable COPD, a study was conducted to evaluate whether systemic corticosteroids improved spirometry results and/or arterial blood-gas levels in patients with COPD and acute respiratory distress. ${ }^{26}$ In this study, patients hospitalized with 
acute respiratory insufficiency and COPD were randomized to receive either intravenous (IV) methylprednisolone $(n=22)$ or matching placebo $(n=22)$ for 72 hours. All patients received standardized treatment consisting of oxygen, aminophylline, nebulized isoproterenol, and antibiotics. The mean percentage change in both pre- and postbronchodilator forced expiratory volume in 1 second $\left(\mathrm{FEV}_{1}\right)$ was significantly greater in patients receiving methylprednisolone in comparison to placebo at all measured time points. No significant differences were observed in forced vital capacity (FVC), arterial $\mathrm{pH}$, or partial pressure of carbon dioxide $\left(\mathrm{PaCO}_{2}\right)$ between the methylprednisolonetreated and placebo groups. The authors noted, however, that perhaps there were too few patients included in this study to determine such differences. Of the potential adverse events associated with systemic corticosteroid administration, hyperglycemia (mean serum glucose concentration $164 \pm 42 \mathrm{mg} / \mathrm{dL}$ for methylprednisolone-treated patients versus $139 \pm 29 \mathrm{mg} / \mathrm{dL}$ for placebo, $P<0.05)$, acute psychosis $(\mathrm{n}=1)$, and upper gastrointestinal hemorrhage $(n=1)$ were observed. However, only hyperglycemia could be definitively attributed to the administration of methylprednisolone.

Following studies indicating the emergent administration of systemic corticosteroids in AECOPD did not acutely affect $\mathrm{FEV}_{1}$ or rate of hospitalization, ${ }^{27}$ but may reduce the rate of readmission, ${ }^{28,29}$ a small trial was conducted to assess the efficacy of oral corticosteroids in the outpatient treatment of AECOPD. ${ }^{17}$ Patients experiencing AECOPD were randomized to receive either a 9-day course of oral prednisone $(n=13)$ in a tapering dose or matching placebo $(n=14)$. All patients were instructed to increase the dose and frequency of their inhaled $\beta$-agonist. Any patients taking ipratropium, inhaled corticosteroids, and/or theophylline preceding study enrollment were allowed to continue the use of these medications. Antibiotics were prescribed to patients with evidence of infective bronchitis. All patients were examined on study days 3 and 10 as well as at all unscheduled hospital visits during the study period. Measured end points included airflow obstruction (as measured by spirometry), gas exchange, dyspnea, and treatment failure.
Significant increases in $\mathrm{FEV}_{1}$ were observed at both day 3 and 10 in patients receiving prednisone in comparison to placebo (184 mL versus $-14 \mathrm{~mL}[P=0.05]$ and $383 \mathrm{~mL}$ versus $9 \mathrm{~mL}[P=0.01]$, respectively). In addition to significantly improving the rate of airflow recovery, prednisone treatment significantly improved gas exchange (as measured by partial pressure of oxygen arterial blood $\left[\mathrm{PaO}_{2}\right]$ ) at both days 3 and 10 in comparison with placebo. There was, however, no difference in $\mathrm{PaCO}_{2}$ response between the prednisone-treated group and placebo. Although there was a trend toward more rapid improvement with prednisone, the degree of dyspnea did not differ significantly between the prednisone-treated group and placebo. The rate of treatment failure in the placebo group was $57 \%(n=8)$ versus 0 in the prednisone group.

In a prospective double-blind study designed to determine if the administration of systemic corticosteroids hastened recovery, patients hospitalized for AECOPD were randomized to receive either $30 \mathrm{mg}$ oral prednisolone once daily $(\mathrm{n}=29)$ or matching placebo $(n=27)$ for 14 days. ${ }^{16}$ All patients received standard treatment with controlled oxygen, nebulized short-acting $\beta$-agonist (salbutamol), and an anticholinergic (ipratropium) every 6 hours, and antibiotics as per the admitting physician's discretion. Any patient receiving an inhaled corticosteroid at the time of study enrollment was allowed to continue this therapy. Patients were followed until hospital discharge, and then reexamined 6 weeks after admission. Spirometry, health status, and length of hospital stay were assessed.

At discharge, postbronchodilator percentage predicted $\mathrm{FEV}_{1}$ in patients receiving prednisolone had increased significantly in comparison to placebo (47\% increase versus $25 \%$ increase, respectively; $P<0.05$ ). Until day 5 , postbronchodilator $\mathrm{FEV}_{1}$ of the corticosteroid-treated group increased at a significantly accelerated rate compared to placebo $(90 \mathrm{~mL}$ per day [50.8-129.2] versus $30 \mathrm{~mL}$ per day [10.4-49.6], $P=0.048)$. Health-status scores had improved significantly in both groups by hospital discharge. Patients receiving prednisolone had a significantly shorter median length of hospitalization when compared to placebo ( 7 days versus 9 days, respectively; $P=0.027)$. At 6 weeks, there was no significant

Table I Current guideline recommendations for systemic corticosteroids in acute exacerbations of chronic obstructive pulmonary disease

\begin{tabular}{lllll}
\hline & $\begin{array}{l}\text { Global initiative for chronic } \\
\text { Obstructive Lung Disease }\end{array}$ & $\begin{array}{l}\text { American Thoracic Societyl } \\
\text { European Respiratory Society }^{7}\end{array}$ & $\begin{array}{l}\text { UK National Institute for } \\
\text { Health and Care Excellence }{ }^{13}\end{array}$ & $\begin{array}{l}\text { Canadian Thoracic } \\
\text { Society }^{14}\end{array}$ \\
\hline Drug & Prednisolone & Prednisone & Prednisolone & Prednisone, or equivalent \\
Dose & $30-40 \mathrm{mg}$ & $30-40 \mathrm{mg}$ & $30 \mathrm{mg}$ & $25-50 \mathrm{mg}$ \\
Duration & $10-14$ days & $10-14$ days & $7-14$ days & $10-14$ days \\
$\begin{array}{l}\text { Year guideline } \\
\text { updated }\end{array}$ & 2013 & 2011 & 2010 & 2008 \\
\hline
\end{tabular}


Table 2 Summary of select clinical trials for systemic corticosteroids compared with placebo

\begin{tabular}{|c|c|c|c|c|c|}
\hline Trial & Design & Intervention & $\begin{array}{l}\text { Baseline patient } \\
\text { characteristics }\end{array}$ & Primary outcomes/results & $\begin{array}{l}\text { Selected secondary } \\
\text { outcomes }\end{array}$ \\
\hline Albert et al $\left.\right|^{26}$ & $\begin{array}{l}\mathrm{R}, \mathrm{DB}, \mathrm{PC} \\
\mathrm{n}=44\end{array}$ & $\begin{array}{l}\text { IV methylprednisolone } \\
0.5 \mathrm{mg} / \mathrm{kg} \text { every } 6 \text { hours } \\
\text { for } 72 \text { hours versus placebo }\end{array}$ & $\begin{array}{l}\text { Mean age } 62 \text { years } \\
\mathrm{FEV}_{1}=0.72 \mathrm{~L}\end{array}$ & $\begin{array}{l}\text { - Change in FEV, significantly higher } \\
\text { for methylprednisolone versus } \\
\text { placebo }(220 \mathrm{~mL}, P<0.00 \mathrm{I})\end{array}$ & $\begin{array}{l}\text { No observed } \\
\text { differences in } \mathrm{FVC} \text {, } \\
\text { arterial } \mathrm{pH} \text {, or } \mathrm{PaCO}_{2}\end{array}$ \\
\hline $\begin{array}{l}\text { Thompson } \\
\text { et } \mathrm{al}^{17}\end{array}$ & $\begin{array}{l}R, D B, P C \\
n=27\end{array}$ & $\begin{array}{l}\text { Oral prednisone taper: } \\
60 \mathrm{mg} \times 3 \text { days, } \\
40 \mathrm{mg} \times 3 \text { days, } \\
20 \mathrm{mg} \times 3 \text { days } \\
\text { versus placebo }\end{array}$ & $\begin{array}{l}\text { Mean age } 67.8 \text { years } \\
\mathrm{FEV}_{1}=1.3 \mathrm{~L}\end{array}$ & $\begin{array}{l}\text { - Change in } \mathrm{PaO}_{2} \text { versus placebo } \\
(1.12 \mathrm{mmHg} / \text { day versus } \\
-0.03 \mathrm{mmHg} / \text { day, } P=0.002) \\
\text { - Change in } \mathrm{A}-\mathrm{aD}_{\mathrm{O} 2} \text { versus placebo } \\
(-1.16 \mathrm{mmHg} / \text { day versus } \\
-0.03 \mathrm{mmHg} / \text { day, } P=0.04) \\
\text { - } \mathrm{FEV}, 0.05 \mathrm{~L} / \text { day versus } 0 \mathrm{~L} / \text { day } \\
(P=0.006) \\
\text { - } \mathrm{PEF} 0.15 \mathrm{~L} / \mathrm{s} / \text { day versus } \\
0.04 \mathrm{~L} / \mathrm{s} / \text { day }(P=0.009)\end{array}$ & \\
\hline Davies et al ${ }^{16}$ & $\begin{array}{l}\mathrm{R}, \mathrm{DB}, \mathrm{PC} \\
\mathrm{n}=56\end{array}$ & $\begin{array}{l}\text { Oral prednisolone } 30 \mathrm{mg} \\
\text { once daily } \times 14 \text { days } \\
\text { versus placebo }\end{array}$ & $\begin{array}{l}\text { Mean age } 67 \text { years } \\
\mathrm{FEV}_{1}=0.59 \mathrm{~L}\end{array}$ & $\begin{array}{l}\text { Predicted FEV, increased } \\
\text { from } 28.2 \% \text { to } 4 \mathrm{I} .5 \% \text { in the } \\
\text { corticosteroid group }(P<0.00 \mathrm{I})\end{array}$ & $\begin{array}{l}\text { Hospital stays were } \\
\text { shorter in the } \\
\text { corticosteroid group }\end{array}$ \\
\hline $\begin{array}{l}\text { Niewoehner } \\
\text { et } \mathrm{al}^{30}\end{array}$ & $\begin{array}{l}R, D B, P C \\
n=27 I\end{array}$ & $\begin{array}{l}\text { Oral glucocorticoid for } \\
2 \text { weeks versus } 8 \text { weeks } \\
\text { versus placebo }\end{array}$ & $\begin{array}{l}\text { Mean age } 67.6 \text { years } \\
\mathrm{FEV}_{1}=0.77 \mathrm{~L}\end{array}$ & $\begin{array}{l}\text { Rate of treatment failure } \\
\text { glucocorticoids versus placebo } \\
\text { at } 30 \text { days ( } 23 \% \text { versus } 33 \% \text {, } \\
P=0.04 \text { ) and } 90 \text { days }(37 \% \\
\text { versus } 48 \%, P=0.04)\end{array}$ & $\begin{array}{l}\text { Systemic steroids (in } \\
\text { both groups) associated } \\
\text { with a shorter initial } \\
\text { hospital stay ( } 8.5 \text { days } \\
\text { versus } 9.7 \text { days for } \\
\text { placebo, } P=0.03 \text { ) }\end{array}$ \\
\hline Aaron et $\mathrm{al}^{31}$ & $\begin{array}{l}R, D B, P C \\
n=147\end{array}$ & $\begin{array}{l}\text { Oral prednisone } 40 \mathrm{mg} \\
\text { once daily versus placebo }\end{array}$ & $\begin{array}{l}\text { Mean age } 69 \text { years } \\
\mathrm{FEV}_{1}=\mathrm{I} \mathrm{L}\end{array}$ & $\begin{array}{l}\text { - Rate of relapse at } 30 \text { days was } \\
\text { lower in the prednisone group } \\
\text { versus placebo ( } 27 \% \text { versus } 43 \% \text {, } \\
P=0.05)\end{array}$ & $\begin{array}{l}\text { Change in } \\
\text { postbronchodilator } \\
\text { FEV, from day I to day } \\
10 \text { prednisone versus } \\
\text { placebo }(34 \% \text { versus } \\
15 \%, P=0.007)\end{array}$ \\
\hline
\end{tabular}

Abbreviations: $\mathrm{A}-\mathrm{aD}_{\mathrm{O} 2}$, alveolar-arterial oxygen gradient; $\mathrm{COPD}$, chronic obstructive pulmonary disease; $\mathrm{DB}$, double blind; $\mathrm{FEV}$, forced expiratory volume in I second; $\mathrm{IV}$, intravenous; $\mathrm{PaO}_{2}$, arterial $\mathrm{PO}_{2} ; \mathrm{PC}$, placebo controlled; $\mathrm{PEF}$, peak expiratory flow; $\mathrm{R}$, randomized; s, second.

difference in percentage predicted postbronchodilator $\mathrm{FEV}_{1}$ or health status in either the corticosteroid-treatment group or placebo in comparison to discharge. In addition, there was no difference in exacerbation rate or rate of hospital admission between the two groups observed at 6 weeks.

A large multicenter trial was conducted to further evaluate the efficacy of systemic corticosteroids for AECOPD. ${ }^{30}$ Within 12 hours of hospital admission, patients were randomized to receive one of three treatments: an 8-week course $(\mathrm{n}=80)$ of systemic glucocorticoids (IV methylprednisolone for 72 hours, followed by once-daily oral prednisone taper over the next 57 days), a 2-week course $(\mathrm{n}=80)$ of systemic glucocorticoids (IV methylprednisolone for 72 hours, followed by once-daily oral prednisone taper over the next 12 days, then placebo for the next 45 days), or placebo $(n=111)$. All patients received a broad-spectrum antibiotic for 7 days. In addition, all patients were required to use an inhaled $\beta$-agonist, inhaled ipratropium bromide, and starting on day 4 , inhaled triamcinolone acetonide at standardized doses for 6 months. The use of high-dose inhaled corticosteroids (other than triamcinolone as part of study protocol), theophylline, or additional open-label systemic corticosteroids was not allowed. Patients were evaluated on each of the first 3 days of hospitalization, and at 2 weeks, 8 weeks and 6 months. The primary end point was a composite of treatment failure, comprised of death from any cause or the need for invasive mechanical ventilation, readmission for exacerbation of COPD, or intensification of pharmacologic therapy. Secondary end points included change in $\mathrm{FEV}_{1}$ and length of hospital stay.

Because there were no differences in outcomes observed between the 8-week and 2-week treatment groups, they were considered equivalent and combined for further analysis. Systemic corticosteroids significantly reduced the rate of first treatment failure compared to placebo at 30 days (23\% versus $33 \%, P=0.04$ ). There was not a significant difference between corticosteroid treatment and placebo at 6 months. $\mathrm{FEV}_{1}$ improved significantly faster in patients receiving systemic corticosteroids than those receiving placebo. The maximum difference in $\mathrm{FEV}_{1}$ (approximately $100 \mathrm{~mL}$ ) 
was observed by the end of day 1 and maintained until day 3 . However, a significant difference was not seen between the active-treatment and placebo groups by the end of 2 weeks. Patients receiving systemic corticosteroids experienced a significantly shorter length of hospital stay in comparison to placebo ( 8.5 versus 9.7 days, $P=0.03$ ). All-cause mortality and COPD-related mortality were similar between the treatment and placebo groups at 6 months. Subgroup analysis revealed that the administration of systemic corticosteroids was associated with more favorable outcomes in patients previously hospitalized for exacerbation of COPD. In these patients, the failure rate at 6 months was $49.5 \%$ for patients treated with glucocorticoids and $66.7 \%$ for those receiving placebo $(P=0.01)$.

Hyperglycemia requiring treatment occurred in a greater proportion of patients treated with systemic corticosteroids in comparison to placebo ( $15 \%$ versus $4 \%, P=0.002$ ). However, when compared to the placebo group, significantly more patients in the corticosteroid-treatment group had a diagnosis of diabetes mellitus, and 16 of the 24 instances of hyperglycemia in the corticosteroid-treatment group occurred in known diabetics. The rate of secondary infections did not differ significantly among the three groups, but the highest percentage of patients with a serious infection occurred in the 8 -week corticosteroid group (13.8\%) in comparison to the 2-week corticosteroid group (1.2\%) and placebo (3.6\%).

Following the results of two randomized clinical trials ${ }^{16,30}$ that suggested systemic corticosteroids prevent treatment failure and reduce the length of hospital stay in AECOPD, a study designed to assess the effect of systemic corticosteroid administration on relapse rates, lung function, and healthrelated quality of life following discharge from the emergency department was carried out. ${ }^{31}$ Prior to discharge from the emergency department, patients presenting with an AECOPD were randomized to receive either oral prednisone once daily for 10 days $(n=74)$ or matching placebo $(n=73)$. After being counseled on proper inhaler technique, all patients received a standardized regimen of an inhaled $\beta$-agonist (albuterol) and an inhaled anticholinergic (ipratropium) via a metereddose inhaler with a valved holding chamber for 30 days. In addition, all patients completed a 10-day course of oral broad-spectrum antibiotics. Patients were allowed to continue all medications they were taking prior to study enrollment, including inhaled corticosteroids. Patients were assessed 3,10 , and 30 days after randomization. The primary study outcome was treatment failure, as defined by an unscheduled health care visit or return to the emergency room secondary to worsening dyspnea within 30 days of randomization.
Secondary outcomes included change from day 1 to day 10 in postbronchodilator $\mathrm{FEV}_{1}$, severity of dyspnea, and COPDspecific quality of life.

In comparison to placebo, oral prednisone significantly reduced the rate of relapse at 30 days (27\% versus $43 \%$, $P=0.05)$. The relative risk of relapse with prednisone treatment at 30 days was 0.63 (95\% confidence interval [CI] 0.40-1.01). Prednisone significantly prolonged the time to relapse compared with placebo (hazard ratio [HR] 0.56, 95\% CI $0.32-0.99 ; P=0.04)$. Although treatment with prednisone did not induce a significant improvement in the total qualityof-life score compared to placebo, the administration of prednisone was associated with a significant improvement in dyspnea. Patients receiving prednisone had significant improvement in lung function at day 10 when compared to placebo (mean $\mathrm{FEV}_{1}$ increase of $34 \%$ in prednisone-treated group versus $15 \%$ in placebo group, $P=0.007$ ). There was no significant difference in hospitalization rates between the two groups $(21 \%$ of patients in the placebo group required hospitalization for COPD within 30 days compared to $11 \%$ in the prednisone group). Significantly more patients receiving prednisone reported insomnia, increased appetite, and weight gain in comparison to placebo $(P<0.01)$. A subgroup analysis revealed that patients taking inhaled corticosteroids were more likely to respond to systemic corticosteroid therapy (relative risk of 30-day relapse 0.44 , 95\% CI 0.22-0.86).

A systematic review of eleven studies $(n=1,081)$, including each of the aforementioned studies, found that systemic corticosteroids significantly reduced the risk of treatment failure (odds ratio [OR] 0.48, 95\% CI, 0.34-0.68) and relapse (HR 0.78, 95\% CI 0.63-0.97) within 30 days in AECOPD. ${ }^{32}$ In addition, treatment with systemic corticosteroids in AECOPD hastened recovery (significantly increased $\mathrm{FEV}_{1}$ by a mean of $140 \mathrm{~mL}$ [95\% CI 90-190 mL] at 72 hours in comparison to placebo), thereby decreasing length of hospital stay (-1.22 days, $95 \% \mathrm{CI}-2.26$ to -0.18$)$. Systemic corticosteroids did not significantly affect mortality, but did increase the likelihood of adverse events (OR 2.33, 95\% CI 1.60-3.40). This systematic review concluded that evidence supported the early administration of systemic corticosteroids in the treatment of AECOPD, but because of the considerable heterogeneity of the included studies, could not offer a recommendation regarding optimal duration, dose, or route.

\section{Duration of therapy}

Following clinical trials documenting the efficacy of systemic corticosteroids in the treatment of AECOPD, studies were conducted in an attempt to establish the optimal treatment 
duration. A parallel-group, single-blind, single-center study compared the efficacy of different durations of corticosteroid therapy in improving airflow obstruction and gas exchange, relieving symptoms, and preventing recurrence in patients with AECOPD $(n=36) .{ }^{33}$ Patients with severe COPD were randomized to receive IV methylprednisolone for 3 days or tapered over 10 days. All patients were hospitalized for at least 10 days, and received a high-dose inhaled $\beta$-agonist, ipratropium, theophylline, and histamine $\mathrm{H}_{2}$-receptor antagonists. Antibiotics were administered if indicated. Primary outcomes were postbronchodilator $\mathrm{FEV}_{1}$ and $\mathrm{PaO}_{2}$ levels on days 3 and 10. Secondary outcomes included symptoms related to exacerbation of COPD (eg, dyspnea, cough), recurrence of exacerbation within 6 months of study enrollment, and treatment-related adverse events.

While $\mathrm{FEV}_{1}$ in both treatment groups increased significantly from baseline, the increase in $\mathrm{FEV}_{1}$ in the 10-day treatment group was significantly higher than the increase in the 3-day treatment group ( $236 \mathrm{~mL}$ versus $68 \mathrm{~mL}, P=0.019$ ). Compared to baseline, there was significant symptom-score improvement in both the 3-day and 10-day treatment groups. Symptoms related to exacerbation of COPD were significantly better in the 10-day treatment group compared to the 3 -day treatment group $(P=0.009)$. There was no observed difference in the rate of recurrence between the treatment groups at 6 months (35\% in 3-day treatment group versus $29 \%$ in 10 -day treatment group). There was no significant difference in the rate of hyperglycemia between the two treatment groups. However, one patient in the 10-day treatment group developed steroid-associated psychosis.

A systematic review comprised of two published studies (including the aforementioned trial) and two published abstracts ( $\mathrm{n}=146)$ inconclusively found no significant difference in the risk of treatment failure between a short duration (7 days or less) and longer duration (greater than 7 days) of corticosteroid therapy in the treatment of AECOPD (OR 0.82 , 95\% CI 0.24-2.79). ${ }^{34}$ In addition, the mean difference in $\mathrm{FEV}_{1}$ did not differ significantly by treatment duration, nor did the likelihood of an adverse event.

Considering data that suggested a short course of systemic corticosteroids was not associated with worse outcomes in comparison to longer treatment courses in the treatment of AECOPD, ${ }^{33,34}$ a noninferiority trial was conducted to evaluate the efficacy of a reduced duration of systemic corticosteroid therapy in comparison to conventional systemic corticosteroid treatment. ${ }^{35}$ All patients presenting with AECOPD were given a one-time dose of IV methylprednisolone on day 1 , and then randomized to receive oral prednisone once daily to complete a total of either 5 days $(n=155)$ or $14(n=156)$ days of systemic corticosteroid therapy. In addition to systemic corticosteroids, all patients received an inhaled $\beta_{2}$-agonist twice daily, tiotropium once daily, and inhaled glucocorticoids twice daily throughout the study. All patients received a broad-spectrum antibiotic for 7 days and as-needed nebulized short-acting bronchodilators while hospitalized. Patients were assessed daily while hospitalized and on days $6,15,30,90$, and 180 following hospital discharge. The primary end point was time to next COPD exacerbation during a follow-up of 6 months. Secondary end points included all-cause mortality, change in $\mathrm{FEV}_{1}$, cumulative corticosteroid dose, and clinical performance. Duration of hospital stay and corticosteroidrelated adverse effects were also assessed. Noninferiority was defined a priori as an HR of less than 1.515.

The majority of study participants were classified as GOLD COPD grade 4 (52.1\%); mean baseline $\mathrm{FEV}_{1}$ was $31.5 \%$ predicted. Time to exacerbation did not differ significantly between a 5-day course of systemic corticosteroids and a 14-day course. A total of 56 patients (35.9\%) experienced AECOPD within 6 months of hospital discharge in the short-term group compared to 57 patients (36.8\%) in the conventional treatment group (HR 0.95 per intent-to-treat analysis, $90 \%$ CI $0.7-1.29 ; P=0.006$ ). Among patients who experienced re-exacerbation of COPD during follow-up, the median time to event was 43.5 days in the short-term group and 29 days in the conventional treatment group.

Overall survival did not differ between the two treatment groups, nor did the need for mechanical ventilation during hospitalization. Alleviation of dyspnea and improvement of bronchitis-associated quality of life and patient-assessed overall performance occurred over the first 5 days of treatment, and did not vary significantly between the two groups. Patients randomized to receive short-term systemic corticosteroid treatment had a significantly shorter duration of hospital stay (median duration of hospital stay of 8 days, 95\% CI 7-9 days) compared to patients receiving conventional systemic corticosteroid treatment (median duration of hospital stay of 9 days, $95 \%$ CI $8-10$ days; $P=0.04)$. FEV improved significantly from baseline to day 6 , and remained stable thereafter in both groups. Although patients receiving conventional therapy were exposed to significantly higher cumulative doses of systemic corticosteroids (median cumulative prednisone dose of $379 \mathrm{mg}$ versus $560 \mathrm{mg}$ in the shortterm therapy and conventional therapy groups, respectively; $P<0.001)$, a detectable difference in corticosteroid-related adverse events between the two groups was not reported. New or worsening hyperglycemia was observed in 74 patients 
$(56.9 \%)$ in the short-term and 74 patients $(57.4 \%)$ in the conventional treatment group $(P>0.99)$; hypertension developed or worsened in 15 patients $(11.6 \%)$ in the shortterm and 23 patients (17.8\%) in the conventional treatment group $(P=0.22)$.

\section{Route of administration}

\section{Intravenous versus oral administration}

Current guidelines for the management of COPD recommend low-dose oral corticosteroids for the treatment of exacerbations. ${ }^{5,7,13,14}$ Oral corticosteroids have very good bioavailability (generally $>85 \%$ ) ${ }^{36}$ greater ease of administration, and lower costs. Despite evidence of the efficacy of oral corticosteroids compared to placebo and guideline recommendations, IV corticosteroids are still routinely used for the treatment of AECOPD. ${ }^{5,16}$ Studies comparing IV to oral corticosteroids in the asthma population also support the use of oral steroids. ${ }^{37-39}$ To date, only two studies have directly compared IV and oral regimens for the treatment of AECOPD.

The first was a single-center, double-blind, double-dummy trial that randomized 435 patients hospitalized for AECOPD to equivalent doses of IV or oral prednisolone $(60 \mathrm{mg})$ once daily for 5 days. ${ }^{40}$ After day 5 , all patients were prescribed an oral tapering schedule beginning with prednisolone $30 \mathrm{mg}$ daily. Patients were all older than 40 years of age with at least a 10 pack-year smoking history and evidence of airflow limitation. Those experiencing very severe exacerbations (arterial $\mathrm{pH}<7.26$ or $\mathrm{PaCO}_{2}>9.3 \mathrm{kPa}$ ) or with unstable comorbidities were excluded. The primary outcome was treatment failure: a composite end point of all-cause mortality, intensive care unit admission, readmission due to COPD, or intensification of treatment. The proportion of patients experiencing treatment failure in the IV group was $61.7 \%$ compared to $56.3 \%$ in the group receiving oral prednisolone, and was noninferior to IV prednisolone therapy. Secondary outcomes of $\mathrm{FEV}_{1}$, qualityof-life scores, and length of hospital stay were comparable between the two groups. The use of equipotent doses of IV and oral corticosteroids provides data to support the use of the oral route for the treatment of COPD exacerbations, when feasible. This finding is further supported by several studies in patients with asthma reporting no benefit with IV corticosteroids compared to oral corticosteroids. ${ }^{37-39}$ The trial did not answer whether high-dose IV corticosteroids are more efficacious than low-dose oral corticosteroids, nor can these findings be applied to patients experiencing very severe exacerbations, as they were excluded from this trial.

A large observational study utilizing claims data from 414 US hospitals evaluated the effects of high-dose IV corticosteroids versus low-dose oral corticosteroids in 79,985 patients hospitalized for AECOPD. ${ }^{12}$ Patients were identified for inclusion by International Classification of Diseases, ninth revision, clinical modification codes representative of AECOPD, and received either low-dose oral corticosteroids (20-80 mg of prednisone equivalents daily) or high-dose IV corticosteroids (120-180 mg of prednisone equivalents daily) as initial therapy (hospital days 1-2). Key exclusion criteria included initial admission to the intensive care unit, diagnosis of pneumonia or pulmonary embolism, hospitalization less than 2 days, and transfer from other acute care facilities. The primary outcome was a composite end point of treatment failure, including mechanical ventilation after day 2, inpatient mortality, or readmission within 30 days for AECOPD. Ninety-two percent of patients $(73,765)$ were initially treated with high-dose IV corticosteroids, whereas only $8 \%(6,220)$ were treated with low-dose oral corticosteroids. Median total corticosteroid doses for the first 2 days of hospitalization were $600 \mathrm{mg}$ and $60 \mathrm{mg}$ of prednisone equivalents for the IV and oral groups, respectively. The use of oral corticosteroids was not associated with greater rates of treatment failure, but was associated with lower hospital cost and length of stay. Limitations of this study were its observational design and use of claims data that did not allow the investigators to adjust for clinical findings. This study also excluded patients admitted to the intensive care unit, so these findings should not be applied to this population.

These studies, in addition to the high bioavailability of corticosteroids and the vast literature supporting the efficacy of corticosteroids in asthma exacerbations, provide evidence to support the use of low-dose oral corticosteroids for the treatment of patients hospitalized for AECOPD who are not admitted to the intensive care unit.

\section{Inhaled corticosteroids}

Although low-dose oral corticosteroids are recommended for AECOPD, systemic exposure predisposes patients to a significant adverse-effect profile. Adverse effects, such as hyperglycemia, myopathy, osteoporosis, thinning of the skin, and posterior subscapular cataract formation, more than any other factor, are most influenced by cumulative steroid dose. Those with frequent exacerbations are of particular concern, as they receive multiple courses of corticosteroid treatment and often higher-dose regimens to control acute exacerbations. ${ }^{41}$

As an alternative to systemic steroids, nebulized corticosteroids have minimal bioavailability, negligible systemic absorption, and minimal systemic adverse effects. ${ }^{41}$ In addition, inhaled corticosteroids have a high level of anti- 
inflammatory activity at the local level. ${ }^{42,43}$ Currently, GOLD guidelines offer nebulized budesonide as an alternative to oral corticosteroids for the treatment of exacerbations.

Maltais et al were among the first to compare nebulized budesonide to oral prednisolone in AECOPD. ${ }^{44}$ In their double-blind, randomized, placebo-controlled trial, they compared nebulized budesonide, oral prednisolone, and placebo in 199 patients requiring hospital admission for AECOPD. Patients were randomized to one of three treatment groups: 1) nebulized budesonide 2 mg every 6 hours for 72 hours (plus placebo tablets), then inhaled budesonide $2 \mathrm{mg}$ for 7 days, 2) prednisolone $30 \mathrm{mg}$ by mouth every 12 hours (plus placebo nebulization), then prednisolone $30 \mathrm{mg}$ by mouth daily for 7 days, or 3) placebo group (placebo tablets + placebo nebulization). All patients were administered terbutaline or salbutamol/ipratropium nebulizer treatment after receiving one of the three study drugs, as well as antibiotics and supplemental oxygen.

The primary end point was change in postbronchodilator $\mathrm{FEV}_{1}$ at 72 hours. Clinical success was predefined as an increase in $\mathrm{FEV}_{1}$ of at least $0.15 \mathrm{~L}$ and a reduction of $\mathrm{PaCO}_{2}$ of at least $5 \mathrm{mmHg}$. The mean change in postbronchodilator $\mathrm{FEV}_{1}(95 \% \mathrm{CI})$ at 72 hours was greater with active treatments than with placebo: budesonide versus placebo, $0.10 \mathrm{~L}(0.02-0.18 \mathrm{~L})$; prednisolone versus placebo, $0.16 \mathrm{~L}$ (0.08-0.24 L). The difference in $\mathrm{FEV}_{1}$ between budesonide and prednisolone was not significant, at $-0.06 \mathrm{~L}(-0.14$ to $0.02 \mathrm{~L}$ ). Rates of adverse events were similar in all three groups. As expected, a greater percentage of patients developed hyperglycemia in the prednisone group $(n=7)$ versus budesonide $(\mathrm{n}=1)$. In summary, nebulized budesonide and prednisone improved airflow limitation versus placebo.

Gunen et al also evaluated nebulized budesonide as an alternative to systemic corticosteroids. ${ }^{41}$ In this prospective study, patients were also randomized into three groups: group 1 received standard bronchodilator therapy (SBDT), group 2 received $40 \mathrm{mg}$ of prednisolone plus SBDT, and group 3 received 1,500 $\mu \mathrm{g}$ of nebulized budesonide plus SBTD. Improvement during 10-day hospitalization was compared with exacerbation and hospitalization rates postdischarge.

Similar to the previous study, the recovery rate in terms of both spirometry and arterial blood-gas results did not differ between the nebulized budesonide and systemic prednisone group. However, patients in the systemic prednisolone group did experience a significant upward trend in blood glucose.

Although GOLD guidelines now list nebulized budesonide as an alternative yet expensive option to oral corticosteroids, larger studies are needed to confirm the long-term impact of clinical outcomes of nebulized corticosteroids for AECOPD, as well as to differentiate nebulized steroid choice and optimal dosage.

\section{Conclusion}

COPD is a complex and progressive disease associated with significant morbidity and mortality. Due to its continuously increasing social and economic burden, significant attention is being paid to the optimal management of the disease and its associated exacerbations. Based on the current body of evidence (Table 2), corticosteroids remain a standard of care for AECOPD secondary to their documented efficacy in improving airflow and gas exchange (increasing $\mathrm{FEV}_{1}$ and $\mathrm{PaO}_{2}$ ), as well as improving dyspnea, hastening recovery, and reducing length of hospitalization and rate of relapse at 30 days. Oral corticosteroids remain preferable to IV corticosteroids, both in terms of cost and ease of administration. This logic is reflected in all major guidelines. . $^{5,13,14} \mathrm{IV}$ corticosteroids remain a viable yet more costly alternative. Until further data are available, the use of nebulized corticosteroids should be reserved for the least severe exacerbations.

Despite a lack of large randomized controlled trials, mounting evidence now suggests a shorter treatment duration of corticosteroids may be beneficial in comparison to the previously recommended extended 10- to 14-day course of therapy. In particular, a recently published randomized, double-blind, placebo-controlled trial found that a 5-day course of systemic corticosteroids was noninferior to the traditional 14-day treatment regimen, in time to exacerbation recurrence. ${ }^{35}$ Additionally, a 5-day course of corticosteroids was associated with a decreased length of hospital stay in comparison to a 14-day course (median 8 days' versus 9 days' hospitalization, respectively; $P=0.04$ ). Given these data, it is likely many patients are unnecessarily exposed to the adverse effects of corticosteroids with extended treatment durations. Although clinical judgment must ultimately play a role in determining the appropriate use and most optimal regimen of corticosteroids in the treatment of AECOPD, we advocate the use of an oral corticosteroid (40 mg of prednisone or equivalent) for 5 days in patients experiencing AECOPD severe enough to seek emergent care.

Numerous questions remain to be answered regarding the use of corticosteroids for AECOPD. Despite AECOPD being one of the most common causes of hospital admission, head-to-head data comparing corticosteroid selection and 
dose are lacking. Future research should continue to look for opportunities to use the lowest effective corticosteroid dose and duration possible.

\section{Disclosure}

Christopher K Finch is a speaker for GlaxoSmithKline. The other authors report no conflicts of interest in this work. All work related to the manuscript was completed as part of the authors' regular job duties. No additional funding was used in the preparation of the manuscript.

\section{References}

1. Halbert RJ, Natoli JL, Gano A, Badamgarav E, Buist AS, Mannino DM. Global burden of COPD: systematic review and meta-analysis. Eur Respir J. 2006;28:523-532.

2. National Heart, Lung, and Blood Institute. Morbidity and Mortality: Chart Book on Cardiovascular, Lung, and Blood Diseases. Bethesda (MD): US Department of Health and Human Services, Public Health Service, National Institutes of Health; 2012. Available from: http:// www.nhlbi.nih.gov/resources/docs/cht-book.htm. Accessed March 17, 2014.

3. Mathers C, Boerma T, Fat DM. The Global Burden of Disease: 2004 Update. Geneva: World Health Organization; 2008.

4. Murphy SL, Xu JQ, Kochanek KD. Death: preliminary data for 2008. Natl Vital Stat Rep. 2012;60:1-51.

5. Global initiative for chronic Obstructive Lung Disease (GOLD). Global Strategy for the Diagnosis, Management, and Prevention of Chronic Obstructive Pulmonary Disease. Bethesda (MD); 2013. Available from: http://www.goldcopd.org/uploads/users/files/GOLD_Report_2013_ Feb20.pdf. Accessed March 17, 2014.

6. Guarascio AJ, Ray SM, Finch CK, Self TH. The clinical and economic burden of chronic obstructive pulmonary disease in the USA. Clinicoecon Outcomes Res. 2013;5:235-245.

7. American Thoracic Society/European Respiratory Society. Standards for the Diagnosis and Management of Patients with COPD. Version 1.2. New York: American Thoracic Society; 2004 (updated 2005). Available from: http://www.thoracic.org/go/copd. Accessed March 17, 2014.

8. O'Reilly JF, Williams AE, Holt K, Rice L. Defining COPD exacerbations: impact on estimation of incidence and burden in primary care. Prim Care Respir J. 2006;15:346-353.

9. Johnston AK, Mannino DM. Epidemiology of COPD exacerbations. In: Wedzicha JA, Martinez FJ, editors. Exacerbations of Chronic Obstructive Pulmonary Disease. London: Informa Healthcare; 2008:15-26.

10. Donaldson GC, Seemungal TA, Bhowmik A, Wedzicha JA. Relationship between exacerbation frequency and lung function decline in chronic obstructive pulmonary disease. Thorax. 2002;57:847-852.

11. Suissa S, Dell'aniello S, Ernst P. Long-term natural history of chronic obstructive pulmonary disease: severe exacerbations and mortality. Thorax. 2012;67:957-963.

12. National Institute for Health and Care Excellence. Chronic obstructive pulmonary disease: Management of chronic obstructive pulmonary disease in adults in primary and secondary care (partial update). 2010. Available from: http://guidance.nice.org.uk/cg101. Accessed March 17, 2014.

13. Lindenauer PK, Pekow PS, Lahti MC, LeeY, Benjamin EM, Rothberg MB. Association of corticosteroid dose and route of administration with risk of treatment failure in acute exacerbation of chronic obstructive pulmonary disease. JAMA. 2010;303:2359-2367.

14. O’Donnell DE, Hernandez P, Kaplan A, et al. Canadian thoracic society recommendations for management of chronic obstructive pulmonary disease - 2008 update - highlights for primary care. Can Respir J. 2008;15 Suppl A:1A-8A.
15. Evensen A. Management of COPD exacerbations. Am Fam Physician. 2010;81:607-613.

16. Davies L, Angus RM, Calverley PM. Oral corticosteroids in patients admitted to hospital with exacerbations of chronic obstructive pulmonary disease: a prospective randomised controlled trial. Lancet. 1999;354:456-460.

17. Thompson WH, Nielson CP, Calvalho P, Charan NB, Crowley JJ. Controlled trial of oral prednisone in outpatients with acute COPD exacerbation. Am J Respir Crit Care Med. 1996;154:407-412.

18. Al-Habert S, Rogers HJ. Pharmacokinetics of intravenous and oral prednisolone. Br J Clin Pharmacol. 1980;10:503-508.

19. Beeral F, Jick H, Tyler JM. A controlled study of the effect of prednisone on air-flow obstruction in severe pulmonary emphysema. $N$ Engl J Med. 1963;268:226-230.

20. Clifton M, Stuart-Harris CH. Steroid therapy in chronic bronchitis. Lancet. 1962;1:1311-1313.

21. Franklin W, Michelson AL, Lowell FC, Schiller IW. Bronchodilators and corticosteroids in the treatment of obstructive pulmonary emphysema. N Engl J Med. 1958;258:774-778.

22. KIein RC, Salbaggio JE, Kundur VG. The response of patients with "idiopathic" obstructive pulmonary disease and "allergic" obstructive bronchitis to prednisone. Ann Intern Med. 1969;71:711-718.

23. Morgan WK, Rusche E. A controlled trial of the effect of steroids in obstructive airway disease. Ann Intern Med. 1964;61:248-254.

24. Moyes EN, Kershaw RA. Long-continued treatment with tetracycline and prednisolone in chronic bronchitis: a controlled trial. Lancet. 1957;2:1187-1191.

25. Petty TL, Brink GA, Miller MW, Corsello PR. Objective functional improvement in chronic airway obstruction. Chest. 1970;57: 216-223.

26. Albert RK, Martin TR, Lewis SW. Controlled clinical trial of methylprednisolone in patients with chronic bronchitis and acute respiratory insufficiency. Ann Intern Med. 1980;92:753-758.

27. Emerman CL, Connors AF, Lukens TW, May ME, Effron D. A randomized controlled trial of methylprednisolone in the emergency treatment of acute exacerbations of COPD. Chest. 1989;95: 563-567.

28. Bullard MJ, Liaw SJ, Tsai YH, Min HP. Early corticosteroid use in acute exacerbation of chronic airflow limitation. Am J Emerg Med. 1996;14:139-143.

29. Murata GH, Gorby MS, Chick TW, Halperin AK. Intravenous and oral corticosteroids for the prevention of relapse after treatment of decompensated COPD: effect on patients with a history of multiple relapses. Chest. 1990;98:845-849.

30. Niewoehner DE, Erbland ML, Deupree RH, et al. Effect of systemic glucocorticoids on exacerbations of chronic obstructive pulmonary disease. Department of Veterans Affairs Cooperative Study Group. N Engl J Med. 1999;340;1941-1947.

31. Aaron SD, Vandemheen KL, Hevert P, et al. Outpatient oral prednisone after emergency treatment of chronic obstructive pulmonary disease. N Engl J Med. 2003;348:2618-2625.

32. Walters JA, Gibson PG, Wood-Baker R, Hannary M, Walters EH. Systemic corticosteroids for acute exacerbation of chronic obstructive pulmonary disease. Cochrane Database Syst Rev. 2009;(1):CD001288.

33. Sayiner A, Aytemur ZA, Cirit M, Unsal I. Systemic glucocorticoids in severe exacerbations of COPD. Chest. 2001;119:726-730.

34. Walters JA, Want W, Morley C, Soltani A, Wood-Baker R. Different durations of corticosteroid therapy for exacerbations of chronic obstructive pulmonary disease. Cochrane Database Syst Rev. 2011;(10):CD006897.

35. Leuppi JD, Schuetz P, Bingisser R, et al. Short-term vs conventional glucocorticoid therapy in acute exacerbations of chronic obstructive pulmonary disease: the REDUCE randomized clinical trial. JAMA. 2013;309:2223-2231.

36. Czock D, Keller F, Rasche FM, Häussler U. Pharmacokinetics and pharmacodynamics of systemically administered glucocorticoids. Clin Pharmacokinet. 2005;44:61-98. 
37. Harrison BD, Stokes TC, Hart GJ, Vaughan DA, Ali NJ, Robinson AA. Need for intravenous hydrocortisone in addition to oral prednisolone in patients admitted to hospital with severe asthma without ventilator failure. Lancet. 1986;1:181-184.

38. Jónsson S, Kjartansson G, Gislaon D, Helgason H. Comparison of the oral and intravenous routes for treating asthma with methylprednisolone and theophylline. Chest. 1998;94:723-726.

39. Ratto D, Alfaro C, Sipsey J, Glovsky MM, Sharma OP. Are intravenous corticosteroids required in status asthmaticus? JAMA. 1988;260:527-529.

40. de Jong YP, Uil SM, Grotjohan HP, Postma DS, Kerstjens HA, van den Berg JW. Oral or IV prednisolone in the treatment of COPD exacerbations: a randomized, controlled, double-blind study. Chest. 2007;132:1741-1747.
41. Gunen H, Hacievliyagil SS, Yetkin O, Gulbas G, Mutlu LC, In E. The role of nebulised budesonide in the treatment of exacerbations of COPD. Eur Respir J. 2007;29:660-667.

42. Johansson SA, Andersson KE, Brattsand R, Gruvstad E, Hedner P. Topical and systemic glucocorticoid potencies of budesonide, beclomethasone dipropionate and prednisolone in man. Eur J Respir Dis Suppl. 1982;122:74-82.

43. Brogden RN, McTavish D. Budesonide: an updated review of its pharmacological properties and therapeutic efficacy in asthma and rhinitis. Drugs. 1992;44:375-407.

44. Maltais F, Ostinelli J, Borbeau J, et al. Comparison of nebulized budesonide and oral prednisolone with placebo in the treatment of acute exacerbations of chronic obstructive pulmonary disease; a randomized controlled trial. Am J Respir Crit Care Med. 2002;165:698-703.

\section{Publish your work in this journal}

The International Journal of COPD is an international, peer-reviewed journal of therapeutics and pharmacology focusing on concise rapid reporting of clinical studies and reviews in COPD. Special focus is given to the pathophysiological processes underlying the disease, intervention programs, patient focused education, and self management protocols.

\section{Dovepress}

This journal is indexed on PubMed Central, MedLine and CAS. The manuscript management system is completely online and includes a very quick and fair peer-review system, which is all easy to use. Visit http://www.dovepress.com/testimonials.php to read real quotes from published authors.

Submit your manuscript here: http://www.dovepress.com/international-journal-of-copd-journal 